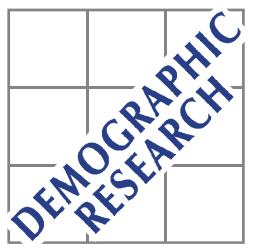

Demographic Research a free, expedited, online journal of peer-reviewed research and commentary in the population sciences published by the Max Planck Institute for Demographic Research Konrad-Zuse Str. 1, D-18057 Rostock · GERMANY www.demographic-research.org

DEMOGRAPHIC RESEARCH

VOLUME 14, ARTICLE 17, PAGES 405-428

PUBLISHED 18 MAY 2006

http://www.demographic-research.org/Volumes/Vol14/17/

DOI: 10.4054/DemRes.2006.14.17

Research Article

Changes in educational assortative mating in contemporary Spain
Albert Esteve
Clara Cortina
(C) 2006 Max-Planck-Gesellschaft. 


\section{Table of Contents}

1 Introduction $\quad 406$

2 Theoretical framework 406

$3 \quad$ Empirical evidence \& research expectations 408

4 Data 411

$5 \quad$ Loglinear models $\quad 413$

6 Results 416

6.1 Trends in educational homogamy 419

6.2 Disappearance of the traditional hypergamic female marriage 423 pattern

$7 \quad$ Summary and discussion $\quad 424$

$8 \quad$ Acknowledgments $\quad 425$

$\begin{array}{ll}\text { References } & 426\end{array}$ 


\title{
Changes in educational assortative mating in contemporary Spain
}

\author{
Albert Esteve ${ }^{1}$ \\ Clara Cortina ${ }^{2}$
}

\begin{abstract}
This article analyses patterns and trends in the educational assortative mating of Spanish women born between 1920 and 1969 using data from the 2001 Spanish Census. By means of loglinear models we examine the following issues: i) intensity and changes in educational assortative mating patterns; ii) crossing barriers across educational thresholds and iii) degree of symmetry between male and female patterns.

Results show that education matters in the composition of unions: people tend to marry assortatively according to their education. However this pattern clearly differs across cohorts and educational groups, being higher for the extreme categories. The most notable trends are 1) the increasing intensity of homogamy among the more educated and 2) the incipient extinction of the traditional female hypergamic pattern.
\end{abstract}

${ }^{1}$ Centre d'Estudis Demogràfics, Universitat Autònoma de Barcelona. E-mail: aesteve@ced.uab.es

${ }^{2}$ PhD Candidate in Demography, Centre d'Estudis Demogràfics, Univeristat Autònoma de Barcelona. E-mail: ccortina@ced.uab.es 


\section{Introduction}

If people were to marry randomly, the probability of an individual marrying in accordance with origin, religion, economic, educational or social status would be solely conditioned by the availability of suitable candidates. The marriage market and its supply and demand of mates would drive the mating process. Nevertheless, scholars agree that individuals do not marry randomly but assortatively in accordance with social and individual characteristics, that is, their origin, religion or educational attainment (Kalmijn, 1998; McCaa, 1993; Mare, 1991; Blossfeld et al., 2003; Smits, Ultee et al.1998; Birkelund, Heldal, 2003; Carabaña, 1994, Esteve, 2005). Individual preferences, institutional influences (family, state and church) and the marriage market itself play an important role in shaping assortative marriage. In contemporary societies, where love is no longer chosen by another's eyes ${ }^{3}$ and where finding a partner is a mainly voluntary action, researchers have accentuated the importance of individual preferences and affinities in explaining patterns of intermarriage and homogamy, although this should not blind us to structural and institutional factors.

In any case, the romantic but fictitious idea of random mating is useful for analytical purposes because it allows one to compare what should be expected under random circumstances with the observed patterns. The results of this comparison shed light on patterns of union formation and assist in the process of hypothesis specification. From this perspective, this article analyses patterns and trends in the educational assortative mating of Spanish women born between 1920 and 1969 using data from the 2001 Spanish Census. Taking advantage of the theoretical framework found in the literature and using loglinear models, we examine the following issues: i) intensity and changes in educational assortative mating patterns; ii) crossing barriers across educational thresholds and iii) degree of symmetry between male and female patterns.

\section{Theoretical framework}

Social scientists see marriage as a reflection of social structure and social change (Kalmijn, 1998). Traditionally, marriage has been a useful mechanism for family strategies to improve or consolidate social position. Despite their historical background, assortative marriages are no longer wholly subordinated to family or community interests. Nowadays, individual preferences and marriage market opportunities play the most important roles in shaping mating processes. By taking into consideration both

\footnotetext{
${ }^{3}$ The expression was borrowed from Shakespeare's "A midsummer night's dream" (Act 1, scene 1).
} 
dimensions we will get a better understanding of how people find a mate. As Oppenheimer (1988, p.572) puts it: "Finding a mate is, in part, a function of the relative numbers and dispersion of available members of the opposite sex. However, people do not want to marry just anyone they want to mate assortatively".

The influence of individual preferences on decisions to marry has largely been developed by the economists of "New Family Economics" following Gary Becker's seminal work A Treatise on the Family (1981). Applying the theory of human rationality to the familiar and intimate decision-making process, mating is defined as an exchange where partners try to maximize their own resources and those of the newly formed union. The optimum, however, is not always achieved because partners face certain restrictions that force them to accept what is merely a good option. These restrictions are imposed, on the one hand, by the normative role still played by the family and social entourage, and, on the other, by the marriage market, which limits marital opportunities through the number of available candidates. Marriage markets are, indeed, the physical and symbolical meeting places of men and women willing to enter a union (Cabré, 1993). Thus, an imbalance in the marriage market will clearly have an effect on mating patterns.

As stated above, the study of marriage is a topic of major interest in a large number of scientific disciplines, including demography, anthropology, economics and sociology, each contributing their own particular view to the study of assortative marriage patterns. Such patterns may be analyzed in accordance with ascribed characteristics, such as family background, religion, or ethnicity, or achieved characteristics, such as levels of educational attainment. In contemporary societies, ascribed characteristics are of decreasing importance in comparison to the predominance of achieved characteristics in raising marital barriers between groups and individuals (Kalmijn, 1998). As an achieved condition, schooling plays a key role in weakening the significance of religion or ethnic background, probably because education is also an indicator of socioeconomic status, which, incidentally, explains the growing interest in considering education into account in most studies of family and marriage.

There are different theories to explain the role of education in assortative mating. From the "New Family Economics" point of view, nuptial unions must be complementary in order to achieve their optimum with the husband specializing in productive work and the wife in reproductive work. Within this framework, the husband's schooling is much more valued than his wife's because of the way it contributes to his professional career. As Oppenheimer (1994) has noted, however, women's entering the labour market has forced us to reconsider this model. The complementary hypothesis is that in a new context where the productive labour of women is more highly valued, men should attach more importance to the schooling of 
women. This change of attitude should have an influence on partner selection and assortative mating patterns. Under these circumstances, a higher degree of homogamy is expected.

Another element contributing to the increase in levels of homogamy is the extension of schooling to young adulthood (Mare, 1991). Staying at school longer increases the chances of meeting and mating with classmates, which means mating with partners of the same educational level. Moreover, the shorter the interval between leaving school and entering union, the higher the probability of forming a homogamous union. This scenario means that higher educated candidates are optimally positioned to marry with the higher educated. This situation forces other groups to marry within their own educational groups, thus, increasing levels of homogamy.

Finally, some scholars have considered macroeconomic variables by establishing links between levels of economic development and patterns of union composition (Smits et al. 1998). This type of approach assumes that education becomes more important for making choices of mates as societies develop and individualism grows. The hypothesis is that levels of homogamy increase in developing countries and decrease when social welfare spreads and, thus, schooling is no longer an indicator of socioeconomic success.

Regardless of the theories and causes that drive assortative mating, researchers are also interested in analyzing its consequences in contemporary societies, which can be observed on an individual or social level. On an individual level, the influence of partners' characteristics and union composition upon family decision making has largely been analyzed with regard to decisions concerning fertility and divorce (González, 2001). On a social level, sociologists have emphasized the role of marriage in the reproduction of social structure (Kalmijn, 1991), regarding union formation as a resource for improving the status of both families and individuals. For assimilation theorists, marriage or, better, intermarrige is conceived both as a cause and a consequence of social assimilation ${ }^{4}$. From this theoretical framework, researchers have largely explored patterns of intermarriage and social interaction between different ethnic, social or racial groups (McCaa, 1993; Pagnini and Morgan, 1990).

\section{Empirical evidence \& research expectations}

Research into educational assortative mating has firstly been focused on the global and specific levels and trends of educational homogamy and secondly on the gender patterns of educational mating. First, global homogamy indexes reflect the propensity

\footnotetext{
${ }^{4}$ In Kalmijn's words “by intermarrying, individuals may lose the negative attitudes they have toward other groups” (Kalmijn 1998, p.396).
} 
of people to marry partners of similar educational attainment, and are measured as summaries of group specific homogamy, which greatly varies throughout educational structure. Thus, the use of specific parameters for each educational category is more appropriate for comparative purposes across time and space. These parameters provide better information about the educational thresholds that restrict intermarriage, which are usually located at both the lower and higher end of the educational hierarchy. Second, differences in gender patterns are measured as propensities to form hypergamous or hypogamous couples, that is, from the female point of view, when women marry up and when women marry down respectively.

All of these questions have been dealt with in a considerable number of case studies and also in some cross-national studies involving countries from all over the world. Even though multiple data and methods were used in these studies, the results as a whole offer a diverse but puzzling perspective of patterns and trends in educational homogamy in different countries during the XXth century, in particular during the last fifty years.

Levels of global educational homogamy tended to remain constant or otherwise to decrease during the final decades of the XXth century in such West European countries as France (Forsé, Chauvel 1995), Great Britain (Halpin, Chan 2003), Norway (Birkelund, Heldal 2003), and Spain (González 2003, Cortina 2004) and in such East European countries as the Czech Republic, Slovakia and Hungary (Katrnák 2005). However, this global and somewhat coincident trend differs from the one described by Schwartz and Mare (2005) for the United States, where there is a long tradition of research into assortative mating. Levels of educational homogamy in the US decreased until 1960 and then started recovering until 2003, as a result of a decrease in intermarriage both of the highest and the lowest educated groups with other educational groups.

Indeed, differences in global trends of homogamy are counterbalanced on the specific level, the homogamy patterns of each educational group being much more similar among them. As in the US, in those European and Latin American countries for which we have evidence, researchers have indicated an increase in homogamy among people with higher levels of educational attainment. This has been related to (i) the increasing number of both men and women with tertiary studies resulting from intense and continued educational expansion; (ii) a decrease in the time-gap between leaving school and entry in union, which is responsible for the major homogeneity of the pool of candidates that study until late (Mare 1991); and (iii) the change in expectations for marriage, which tends towards being gender equal. At the bottom of the educational structure we found some similarities between countries in terms of the less educated, who are universally becoming marginalized in the partner selection process. Therefore, 
the most important barriers are fixed at the top and bottom of the educational hierarchy and the medium educational categories present the lowest levels of homogamy.

Analyses of gender symmetry in marital patterns have mostly been developed in countries where gender inequalities are high, such as, for example, in Latin America, where researchers have particularly analyzed the transformation of the female hypergamic pattern; comparing the cases of Mexico and Brazil, Esteve and McCaa (2005) have shown how levels of homogamy have relaxed in both countries, but that the difference between them lies in the prevalence of the traditional female hypergamic pattern, which has regressed spectacularly in Brazil but has remained active in Mexico. In that sense, the Brazilian transformation is similar to the one previously experienced in such developed countries as the US (Qian 1998), where gender distinctions have lost their strength. Again, changes in mating preferences as a result of the increasing value of female schooling and changes in the educational distribution that filled the gap between men and women are mentioned as major reasons for transforming the classical female hypergamic pattern.

The purpose of our work is to explore educational assortative mating patterns in Spain in the context of the decrease in global homogamy patterns across XXth century Spanish cohorts (Cortina 2004). Using a generalized odds ratio, called H (Bierkelund 2003), Cortina demonstrated how the propensity to marry homogamously in Spain decreased steadily across cohorts by $17 \%$ between the 1920-24 female cohort and that of 1965-69. We are now interested in examining specific homogamy patterns for each educational group and gender differences in assortative mating. Therefore, we ask a) how prone have people been to marry homogamously in accordance with their level of educational attainment and b) how prevalent has the tendency been for women to marry up. Based on previous empirical results for other countries and theories used to explain patterns of educational homogamy, we now approach the treatment of these research questions with some preliminary expectations.

First, we expect the global pattern of homogamy of decrease across cohorts not to apply to the higher educated group, an increase in the marital barrier between the highest educated group and the other categories being expected instead. Our expectation is based on the hypothesis of major gender symmetry in partner choice (both men and women share the same preferences for higher educated candidates in the marriage market, Oppenheimer 1994) and of major homogeneity of the marriage market for the higher educated (Mare 1991).

Second, considering the value acquired by the schooling of women in marital selection and the fact that the educational distribution of women tends to be equal to the distribution of men, we will not expect the traditional pattern of female hypergamy to be maintained. Like in other European countries and especially in those countries, like Brazil (Esteve, McCaa 2005), where educational expansion has considerably reduced 
major educational gender differences, we expect the prevalence of female hypergamy among heterogamous unions to decrease and lead to major heterogeneity and a greater presence of the inverse combination.

\section{Data}

The data used in this research came from the Spanish 2001 Population Censuses, the results of which are distributed in tabular form via the Instituto Nacional de Estadística's website (www.ine.es). The structure of the data is simply the tabulation of unions by the husband's educational attainment, the wife's educational attainment, and the wife's birth cohort (Table 1). For theoretical and analytical reasons, we consider all kind of unions regardless of their de facto or de jure condition. Given that we propose to explore overall interaction patterns and trends between levels of educational attainment, it would be distracting to consider differences between de facto and de jure unions or to take into account other variables, although future research may address these issues. Since consensual unions amount to less than $4 \%$ of the total (with differences between birth cohorts: $1.7 \%$ for $1920-29$ and $7.2 \%$ for 1960-69), distinguishing between the type of union makes little difference. Moreover, consensual unions alone do not produce reliable results given the diversity of forms hidden within them. For instance, only $8.8 \%$ of the females born during 1920-29 and living in consensual union were single. On the other hand, the proportion of single females born during 1960-69 living in consensual union rises to $45.5 \%$. So, to avoid misleading interpretations, the distinct nature of consensual unions would require separate treatment.

The level of educational attainment studied here is the one reported at the time of the census and, thus, it may not be the same as the one at the time the union was formed. However, we do not believe that this factor, imposed by the availability of data, will significantly bias our results because the level of education achieved barely changes after marriage. Marriage typically occurs after leaving school.

From the 10 levels of educational attainment provided by the Spanish 2001 Population Census, we have recoded the initial distribution in five groups: less than primary completed; primary completed (at least 5 years of school); lower secondary (currently the limit of compulsory schooling); higher secondary; and tertiary education. This classification is analytically useful and coherent with the main divisions of the educational system in Spain.

Using the female year of birth as a reference, we constructed five decennial groups of birth cohorts, from 1920-29 to 1960-69, covering a range of ages from 32 to 81 years of age at the time of the census. At 32 years of age, the proportion of ever married or in 
union for a specific cohort is close to its final proportion. By selecting younger ages, there is a risk of not including those individuals that are postponing their union, probably for educational reasons.

Analysis of patterns of homogamy are usually based either on newlyweds obtained from continuous survey or on prevailing marriages from cross-sectional data which are then classified in consideration of the age at marriage or the age of one or both spouses in order to identify temporal changes.

Using data from the 2001 population census to explore patterns of educational assortative mating for prevailing marriages that occurred in the somewhat distant past is, undoubtedly, a source of concern due to likely selection problems, especially among older cohorts. Marital dissolution and educational upgrades after marriage play an increasingly important role in explaining the intensification of the degree of homogamy within cohorts over time (Schwartz, Mare 2003). Research shows that homogamous couples are more stable than heterogamous ones (Kalmijn 1991). Newlywed data from vital statistics would solve this selection problem, but vital statistics in Spain do not report educational attainment of the partners and, moreover, our analysis would have to be limited only to formal unions. So, in Spain, censuses are the most reliable source for our research purposes, even though they have their limitations too.

Unfortunately, the Spanish census of 2001 does not report the age at marriage and, thus, it is not possible to control for the duration of marriage in order to estimate either likely selection biases related to that duration or to the age gap between leaving school and entering a union. We could instead have used previous censuses to compare cohorts at the same age, but microdata is only available for the 1991 census. When microdata for earlier censuses becomes available, it will be possible to test whether, for example, patterns of homogamy for women currently in unions differ significantly from those whose unions were broken, such as the widowed, separated or divorced. We separately analyzed data for the 1991 Population census of Spain to compare educational background within cohorts at two different points in time. For those cohorts born before 1950 there are no substantive differences between the average level of education reported in 2001 compared to 1991, although the average level is systematically higher in 2001. Differences between the two censuses increase for cohorts born from 1950 on as a result of the education attained during this period, but these differences are the same for all living arrangements (in couple, divorced, or widowed). Besides, we tested the same set of loglinear models using the 1991 data and the conclusions from this additional analysis were the same as those reached with the 2001 data that we will present next.

Based on the 2001 data, the effects of widowhood and divorce must be recognized among older cohorts, but it is not readily obvious that the effects of bias introduced by union dissolution on observed patterns of homogamy are significant, that is, that current 
unions are not representative of the distribution at initial formation. Divorce rates among older cohorts are extremely low. The proportion of women either separated or divorced ranges from $0.9 \%$ for the $1920-29$ cohort to $3.1 \%$ for the $1960-69$ cohort. It is worth remembering that in Spain the law authorizing divorce was passed in 1981, so divorce was not an option for most of these couples until that year. Compared to the case of Norway, where a similar approach was taken to explore educational homogamy, divorce rates in Spain are notably lower (Bierkelund 2003).

Estimates of the incidence of remarriage are not readily available from the census microdata. There is a lack of information about first marriages. However, given the singularity of the Spanish case, where divorce is not extended, we expect remarriage rates among older cohorts to be low.

The proportion of women born during 1920-29 who were widowed and not living in unions was $44 \%$ in the 2001 census. For women born one decade later, the proportion drops to $20 \%$. Since there is no evidence that union disruption due to the death of one of the partners is dependent on the degree of similarity between the level of educational attainment of the spouses after controlling for the age gap between them, we do not expect large biases among older cohorts. In any case, as was to be expected, if the propensity for homogamy was higher for couples where neither or only one of the partners survived, selection bias could affect our results by strengthening rather than reversing the overall patterns observed.

By now it should be apparent that our analysis is cross-sectional, not longitudinal. On the other hand, the analysis of educational homogamy using census data taking age into account is tenable because, first, it is widely recognized that education is largely complete by the age of 32 (the youngest age that we consider); second, the incidence of divorce and remariage is relatively low; and, third, we don't expect the probability of widowhood to depend on the similarity of education of the partners. The remaining unions, although observed after they were initiated, are still representative of the original distribution, at least to illustrate the main interaction patterns between different levels of educational attainment.

\section{Loglinear models}

Loglinear models are commonly used to explore patterns of interaction between two or more variables (Knoke and Burke, 1980). Unlike logistic regression analyses (or related methods, such as event history analysis), loglinear models offer three characteristics that make them particularly appropriate for analyzing patterns of assortative marriage. First, loglinear models do not require any distinction between dependent and independent variables. Instead, loglinear models measure the association between two 
or more variables beyond what is imposed by their marginal distributions. Second, loglinear models offer a more comprehensive view of the marriage market, involving all possible interactions without requiring each one to be dealt with separately. The method provides, therefore, a wide-angle vision of the marriage market that does not force segmentation into multiple combinations or transitions that, in most cases, are interdependent. Third, and no less important, loglinear models provide parameters for each specific effect in a hierarchical way, for example, the effect of belonging to group A, the effect of belonging to group B, and the effect of belonging to group A and B at the same time, which, in this case, can be used as an indicator of net association between categories.

Loglinear models allow us to formulate hypotheses of patterns of educational assortative mating. For explanatory purposes, we start with the most basic hypothesis, the model of independence, which can be estimated as follows:

$$
\log f_{i j}=\mu_{0}+\mu_{i}+\mu_{j}
$$

where $\log f_{i j}$ is the natural $\operatorname{logarithm}$ of the expected frequency for row $i$ and column $j$; $\mu_{0}$ the constant; $\mu_{i}$ parameter of row $i ; \mu_{j}$ parameter of column $j$.

In terms of educational homogamy, this model assumes that there is no relationship between educational attainment of men and women net of the marginal distribution of the schooling of the partners. At the other extreme, the saturated model assumes a specific interaction for each and every combination, computing, therefore, as many parameters as there are combinations. In mathematical terms, this model can be formulated as follows:

$$
\log f_{i j}=\mu_{0}+\mu_{i}+\mu_{j}+\mu_{i j}
$$

where $\mu_{i j}$ is the additional parameter of row $i$ and column $j$.

Although the saturated model exactly reproduces the observed data, it is of no substantive interest and offers no parsimony whatsoever. However, between the independent and the saturated models, there are other model arrangements that, with more or less parsimony, may bring some interesting insights to our analysis.

Figure 1 shows the topological structure of the parameter of the main hypothesis explored in this research. Technically, these structures are known by the following names: Quasi-Independence plus corners (E), Crossing parameters (X), Symmetry (S), and Asymmetry $(A)$ which, in this analysis, correspond to Educational Homogamy, Educational Barriers, Gender Symmetry and Female Hypergamy, respectively. 
In a contingency table with two categorical variables that share the same categories, it is common to observe that cells along the diagonal encompass more cases than expected under random circumstances. In this context, it is appropriate to explore the quasi-independence condition that assumes independence everywhere but on the diagonal. Quasi-independence plus corners (E) assumes that the corners, in our case cells $[1,2],[2,1][4,5],[5,4]$, do not fulfill the condition of independence either and must therefore be differentiated from the remaining cells.

The crossing parameters model is used to measure the social distance between spouses by means of estimating the crossing parameters, which allows for an examination of educational intermarriage and heterogamy (Blackwell 1998). The crossing parameters model used in this research suppresses cells [2,2], [3,3], [4,4], which converts it into a quasi-crossing parameters model. Compared with the quasiindependence plus corners model, the quasi-crossing parameters model focuses on movement across educational groups and off-diagonal locations where the former examines the strength of the diagonal effect, thus, the tendency towards educational homogamy. Both models are somewhat complementary but offer different perspectives of educational assortative mating patterns. While the $\mathrm{QI}+\mathrm{C}$ provides a set of parameters for each homogamous educational pairing, the combination of crossing effects reflect the difficulty to marry in a particular educational group. Thus, if homogamy within the higher educated group is high, the difficulty to marry someone with a higher education will also be high. For those interested, Mare (1991), Blackweel (1998) and Qian (1998) offer an extended explanation of how to build the crossing-parameters type of model involved in this paper, although the three papers offer alternative ways of presenting the results.

Finally, the gender symmetry (S) model tests whether the probability of partnering between $i$ and $j$ is the same as that for $j$ and $i$. In other words, taking into account the marginal distribution of the schooling of husbands and wifes, the probability of a marriage between two individuals of unequal schooling is unaltered by whether it is the husband or the wife that has more schooling. In addition, to test the existence of a uniform tendency among men or women to marry up or down, we estimate a female hypergamy parameter (A), following Mare's example (1991). 
Figure 1: $\quad$ Topology of selected models of educational assortative mating

Educational Homogamy (Quasi Independence

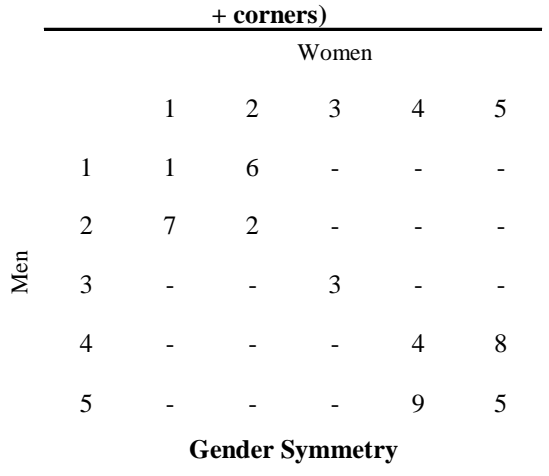

\begin{tabular}{|c|c|c|c|c|c|}
\hline & \multicolumn{5}{|c|}{ Women } \\
\hline & 1 & 2 & 3 & 4 & 5 \\
\hline 1 & - & 1 & 2 & 3 & 4 \\
\hline 2 & 1 & - & 5 & 6 & 7 \\
\hline 3 & 2 & 5 & - & 8 & 9 \\
\hline 4 & 3 & 6 & 8 & - & 10 \\
\hline 5 & 4 & 7 & 9 & 10 & - \\
\hline
\end{tabular}

Educational Barriers (Crossing parameters)

\begin{tabular}{|c|c|c|c|c|c|}
\hline & \multicolumn{5}{|c|}{ Women } \\
\hline & 1 & 2 & 3 & 4 & 5 \\
\hline 1 & - & v1 & v1v2 & $\mathrm{v} 1 \mathrm{v} 2 \mathrm{v} 3$ & $\mathrm{v} 1 \mathrm{v} 2 \mathrm{v} 3 \mathrm{v} 4$ \\
\hline 2 & $\mathrm{v} 1$ & - & v2 & $\mathrm{v} 2 \mathrm{v} 3$ & $\mathrm{v} 2 \mathrm{v} 3 \mathrm{v} 4$ \\
\hline 3 & v1v2 & v2 & - & v3 & $\mathrm{v} 3 \mathrm{v} 4$ \\
\hline 4 & $\mathrm{v} 1 \mathrm{v} 2 \mathrm{v} 3$ & $\mathrm{v} 2 \mathrm{v} 3$ & v3 & - & $\mathrm{v} 4$ \\
\hline 5 & $\mathrm{v} 1 \mathrm{v} 2 \mathrm{v} 3 \mathrm{v} 4$ & $\mathrm{v} 2 \mathrm{v} 3 \mathrm{v} 4$ & $\mathrm{v} 3 \mathrm{v} 4$ & $\mathrm{v} 4$ & - \\
\hline \multicolumn{6}{|c|}{ Female Hypergamy } \\
\hline & \multicolumn{5}{|c|}{ Women } \\
\hline & 1 & 2 & 3 & 4 & 5 \\
\hline 1 & - & - & - & - & - \\
\hline 2 & 1 & - & - & - & - \\
\hline 3 & 1 & 1 & - & - & - \\
\hline 4 & 1 & 1 & 1 & - & - \\
\hline 5 & 1 & 1 & 1 & 1 & - \\
\hline
\end{tabular}

\section{Results}

Table 1 shows the relative distribution of the 8,201,278 Spanish unions considered in our study, by the schooling of both partners and broken down by the wife's birth cohort. A cursory examination of the marginal distributions reveals the dramatic educational expansion experienced by Spanish cohorts in recent decades. During XXth century, the Spanish population increased its overall levels of educational attainment thanks to the promotion of universal access to education and the extension of compulsory schooling to the mid-teens. These processes reduced traditional gender differences, as seen among the younger cohorts. 
Table 1: Distribution of pairings (\%) by partners' level of educational attainment and female birth cohort

\begin{tabular}{|c|c|c|c|c|c|c|c|c|}
\hline \multirow[b]{2}{*}{ Men } & \multicolumn{5}{|c|}{ Women } & \multirow[b]{2}{*}{ Total } & \multirow[b]{2}{*}{$N$} & \multirow[b]{2}{*}{$\begin{array}{c}\% \\
\text { Homogamy }\end{array}$} \\
\hline & $\begin{array}{r}\text { Primary not } \\
\text { completed }\end{array}$ & $\begin{array}{r}\text { Primary } \\
\text { Completed } \\
\end{array}$ & $\begin{array}{r}\text { Lower } \\
\text { Secondary } \\
\end{array}$ & $\begin{array}{r}\text { Higher } \\
\text { Secondary } \\
\end{array}$ & $\begin{array}{r}\text { Tertiary } \\
\text { Education } \\
\end{array}$ & & & \\
\hline $1920-29$ & & & & & & & & \\
\hline Primary not completed & 39,89 & 2,68 & 0,36 & 0,18 & 0,07 & 43,18 & & \\
\hline Primary completed & 5,06 & 30,34 & 0,78 & 0,34 & 0,20 & 36,72 & & \\
\hline Lower Secondary & 1,19 & 2,44 & 6,07 & 0,34 & 0,18 & 10,22 & & \\
\hline Higher Secondary & 0,70 & 1,86 & 1,33 & 1,25 & 0,30 & 5,44 & & \\
\hline Tertiary education & 0,31 & 1,12 & 1,02 & 0,98 & 1,02 & 4,44 & & \\
\hline Total & 47,15 & 38,43 & 9,56 & 3,09 & 1,77 & 100 & 693951 & 78,57 \\
\hline \multicolumn{9}{|l|}{$1930-39$} \\
\hline Primary not completed & 32,94 & 2,71 & 0,51 & 0,19 & 0,07 & 36,42 & & \\
\hline Primary completed & 4,80 & 29,90 & 1,25 & 0,41 & 0,23 & 36,60 & & \\
\hline Lower Secondary & 1,50 & 3,25 & 8,48 & 0,51 & 0,27 & 14,02 & & \\
\hline Higher Secondary & 0,76 & 2,26 & 2,01 & 1,61 & 0,46 & 7,10 & & \\
\hline Tertiary education & 0,27 & 1,19 & 1,43 & 1,33 & 1,65 & 5,86 & & \\
\hline Total & 40,26 & 39,31 & 13,69 & 4,06 & 2,68 & 100 & 1353203 & 74,58 \\
\hline \multicolumn{9}{|l|}{$1940-49$} \\
\hline Primary not completed & 16,92 & 2,40 & 0,90 & 0,21 & 0,07 & 20,50 & & \\
\hline Primary completed & 3,23 & 25,34 & 2,80 & 0,67 & 0,31 & 32,34 & & \\
\hline Lower Secondary & 1,85 & 5,35 & 15,36 & 1,17 & 0,58 & 24,31 & & \\
\hline Higher Secondary & 0,72 & 3,01 & 4,53 & 2,83 & 1,03 & 12,12 & & \\
\hline Tertiary education & 0,21 & 1,23 & 2,74 & 2,40 & 4,16 & 10,73 & & \\
\hline Total & 22,92 & 37,31 & 26,34 & 7,28 & 6,15 & 100 & 1739505 & 64,62 \\
\hline \multicolumn{9}{|l|}{$1950-59$} \\
\hline Primary not completed & 6,34 & 1,50 & 1,00 & 0,26 & 0,08 & 9,19 & & \\
\hline Primary completed & 1,58 & 17,15 & 4,36 & 1,45 & 0,47 & 25,01 & & \\
\hline Lower Secondary & 1,23 & 5,38 & 19,41 & 3,40 & 1,26 & 30,67 & & \\
\hline Higher Secondary & 0,47 & 2,77 & 7,08 & 6,26 & 2,87 & 19,45 & & \\
\hline Tertiary education & 0,11 & 0,74 & 2,63 & 3,76 & 8,44 & 15,69 & & \\
\hline Total & 9,73 & 27,54 & 34,47 & 15,14 & 13,12 & 100 & 2070696 & 57,61 \\
\hline \multicolumn{9}{|l|}{$1960-69$} \\
\hline Primary not completed & 2,31 & 0,78 & 0,67 & 0,28 & 0,07 & 4,11 & & \\
\hline Primary completed & 0,67 & 9,32 & 5,27 & 2,22 & 0,52 & 18,00 & & \\
\hline Lower Secondary & 0,55 & 4,04 & 18,80 & 7,26 & 2,35 & 33,01 & & \\
\hline Higher Secondary & 0,26 & 1,84 & 7,58 & 12,13 & 5,69 & 27,50 & & \\
\hline Tertiary education & 0,06 & 0,29 & 1,67 & 4,56 & 10,79 & 17,38 & & \\
\hline Total & 3,85 & 16,28 & 33,99 & 26,45 & 19,43 & 100 & 2343923 & 53,36 \\
\hline$N$ & & & & & & & 8201278 & \\
\hline
\end{tabular}

Source: 2001 Spanish Census, Spanish National Statistical Institute.

Almost half of the individuals living in union in 2001 and born between 1920 and 1929 did not complete their primary studies, precisely $43 \%$ of men and $47 \%$ of women. At the other extreme, for those born between 1960 and 1969 the proportion that did not complete their primary studies was not even as high as 5\% for men or women. This reduction means that the upper categories, those to have completed primary, but above all secondary and tertiary education, increased greatly. For instance, the proportion of men with secondary studies rose from 16\% (1920-29) to 60\% (1960-69) and for women from 13\% (1920-29) to 60\% (1960-69). Although the transformation was extraordinary, it was always greater for females. The same gendered pattern is observed among the 
higher educated, from 4 to $17 \%$ for men, and from 2 to $19 \%$ for women. For the first time, for the 1960-1969 cohorts, the proportion of women with higher education was greater than that of their partners.

Table 1 also reports the proportion of homogamous unions, those where the husband and wife have the same level of educational attainment. This proportion is obtained by adding all of the frequencies found in the diagonal cells, which involve the vast majority of unions. The overall levels of homogamy decrease across cohorts from 78\% among women born in 1920-1929 to 53\% among women born in 1960-69.

Now we should ask whether this reduction concerns all individuals regardless of their educational attainment level. In order to do so controlling for changes in marginal distributions we rely on loglinear models, which distinguish patterns resulting from changes in marginal distribution, from patterns showing association between the schooling of partners.

\section{Table 2: $\quad$ Likelihood-Ratio Chi-Square Statistics for Selected Models of Educational Assortative Mating}

\begin{tabular}{|c|c|c|c|c|c|}
\hline \multicolumn{3}{|c|}{ Model } & \multirow{2}{*}{$\frac{\mathbf{d f}}{80}$} & \multirow{2}{*}{$\begin{array}{r}\text { G2 } \\
86743,4\end{array}$} & \multirow{2}{*}{$\frac{\text { BIC }}{66401}$} \\
\hline 1. & Baseline model: Independence & $\mathrm{MC}, \mathrm{FC}$ & & & \\
\hline \multicolumn{6}{|c|}{ Homogamy } \\
\hline 2. & 1+Educational Affinity & $\mathrm{MC}, \mathrm{FC}, \mathrm{MF}$ & 64 & 924,2 & 217 \\
\hline 3. & 2+ Edu. Diagonal x Cohort & $\mathrm{MC}, \mathrm{FC}, \mathrm{MF}, \mathrm{DbC}$ & 55 & 208,9 & -419 \\
\hline 4. & 3+ Edu. Diagonal + Corners x Cohort & $\mathrm{MC}, \mathrm{FC}, \mathrm{MF}, \mathrm{EbC}$ & 51 & 82,1 & -496 \\
\hline 5. & 2+ Edu. Crossing Parameters $x$ Cohort & MC, FC, MF, XC & 48 & 505,2 & -59 \\
\hline 6. & $5+$ Edu. Diagonal x Cohort & MC, FC, MF, DC, XC & 36 & 108,2 & -307 \\
\hline \multicolumn{6}{|c|}{ Symmetry } \\
\hline 7. & 1+ Sex Symmetry & $\mathrm{MC}, \mathrm{FC}, \mathrm{S}$ & 70 & 1005,8 & 217 \\
\hline 8. & 7+ Sex Asymmetry Parameter & MC, FC, S, P & 69 & 948,6 & 175 \\
\hline 9. & 7+ Sex Asymmetry Parameter x Cohort & $\mathrm{MC}, \mathrm{FC}, \mathrm{S}, \mathrm{PC}$ & 65 & 577,2 & -183 \\
\hline 10. & 9+ Sex Symmetry x Cohort & $\mathrm{MC}, \mathrm{FC}, \mathrm{SC}, \mathrm{PC}$ & 25 & 37 & -247 \\
\hline
\end{tabular}

Note: df. degrees of freedom; C. Birth Cohort (4); M. Male's Schooling Level (4); F. Female's Schooling Level (4); D. Homogamy Parameters; E. Homogamy Parameters plus corners; X. Crossing Parameters; S. Symmetry Parameters; P. Hypergamy/Hypogamy; b. Uniform Trend 
Table 2 reports Likelihood Ratios Chi-square $\left(\mathrm{G}^{2}\right)$ and Bayesian Indicator Criteria (BIC) for loglinear models of educational assortative mating ${ }^{5}$. For both indicators, the lower the value, the better the goodness of fit and, therefore, the better the model for explaining mating patterns.

We structure the presentation of the results into two parts in accordance with the principal questions underlying our research: 'how prone are people to marry homogamously according to their educational attainment level?' and 'how prevalent is the tendency for women to marry up?' The first question is answered in models 2 to 6 and the second in models 7 to 10 . None of these models would have been necessary if model 1 , which tests the independence hypothesis, fit satisfactorily $(\mathrm{BIC}=66401)$. In other words, model 1 proves that changes in educational assortative mating can not be solely explained by changes in the marginal distribution of the schooling of partners, therefore, Spaniards do not mate at random. Thus, new models need to be specified in order to explain the observed patterns of educational assortative mating better.

\subsection{Trends in educational homogamy}

Model 2 assumes an unrestricted association between male and female schooling that is constant across cohorts. Compared to model 1, it improves the goodness of fit but it is still unsatisfactory in terms of conventional statistical standards $\left(\mathrm{BIC}_{2}=217\right)$.

Models 3 and 4 allow for a change in patterns across cohorts that represents a significant improvement in terms of goodness of fit $\left(\mathrm{BIC}_{3}=-419 ; \mathrm{BIC}_{4}=-496\right)$. Both models show that the association between male and female schooling varies across cohorts and that this association occurs in the diagonal cells (D), model 3, or in the diagonal plus corners (E), model 4 , depending on whether we are using a restricted or extended definition of homogamy.

Models 5 and 6 adopt a different strategy to examine patterns of interaction between educational groups: crossing parameters or educational barriers (X). Crossing parameters measure ease of mating between lower and higher educational groups. Model 5 allows for unrestricted association between male and female levels of educational attainment but adds specific crossing parameters for each cohort. In addition, model 6 includes cohort specific association parameters for the diagonal cells, which improve the goodness of fit $\left(\mathrm{BIC}_{5}=-59 ; \mathrm{BIC}_{6}=-307\right)$. These results show how educational assortative mating patterns have changed and how useful crossing parameters are for detecting and measuring these changes.

${ }^{5}$ To fit our models we have used a representative sample of $10 \%$ of the cases. 
In conclusion, both the homogamy and crossing parameter models prove the existence of a cohort specific assortative pattern of educational mating net of the effect of the marginal distribution of male and female schooling.

Since models 4 and 6 offer the best fit, we will now examine their parameters in detail. Model 4 produces a set of parameters that evaluate the strength of the diagonal and corner cells for attracting more unions than those randomly expected. As figure 2 shows, there are no negative parameters, which means that, after controlling for differences in educational structure, the odds of marriage within each educational group are positive and change across educational groups and cohorts.

The association between pairings that did not complete primary is the highest of all and remains constant across cohorts. At this point, we must remember that educational homogamy is usually higher in extreme categories because marital options here are restricted in just one direction, one ascendant and the other descendant. In any case, this does not apply for associations between higher educated men and higher educated

\section{Figure 2: $\quad$ Homogamy Parameters by Level of Education and} female birth cohort (log odds of Model 4)

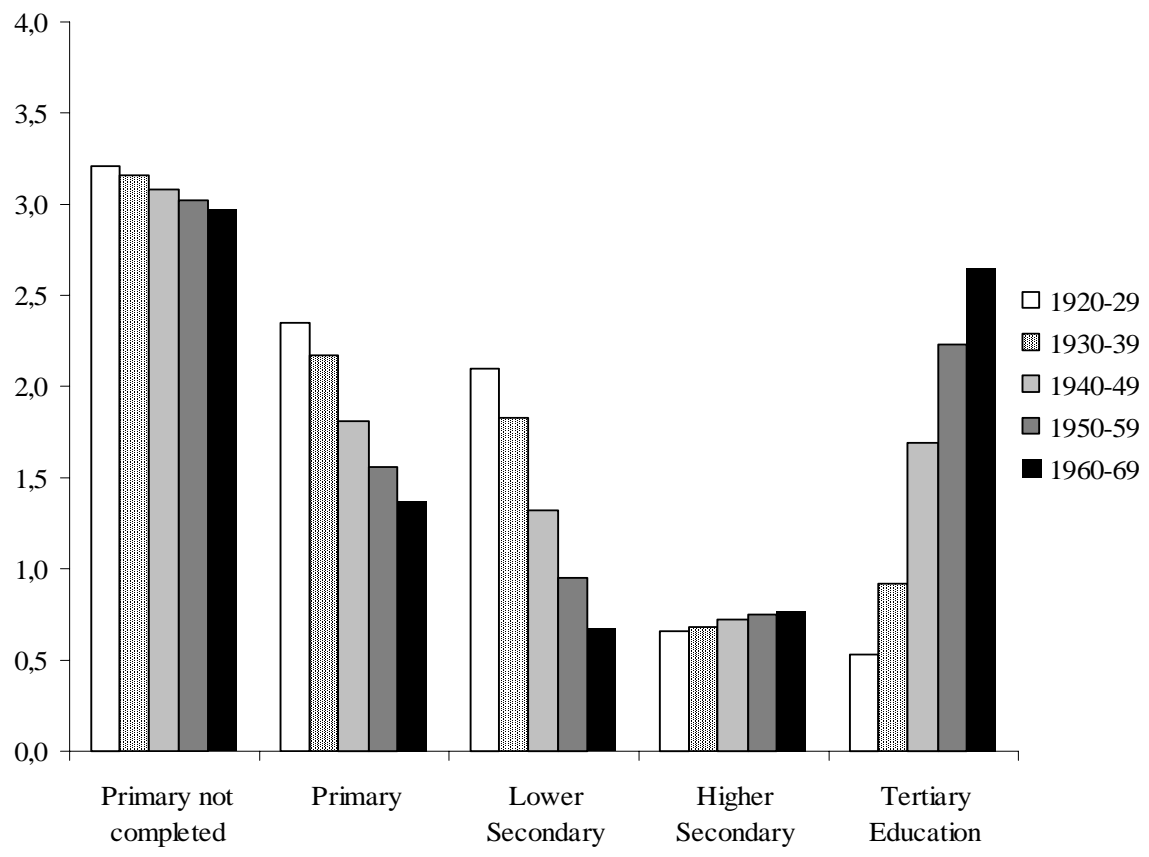


women for the first three cohort groups. Later, among younger cohorts, association among the higher educated group increases. Homogamy levels among individuals with higher secondary studies remain relatively low and constant across cohorts. For future research, we may reconsider the importance of treating "higher secondary" as a separate category and maybe merge it with "lower secondary". Finally, homogamy levels for "primary" and "lower secondary" decrease simultaneously across cohorts.

The crossing parameters model (6) offers a measure of distance between educational groups that can be useful for complementing the results discussed up to this point. By estimating the crossing effects we are able to determine which educational levels present the highest barriers to mixed unions. Figure 3 shows the crossing parameters produced by model 6 , which allow us to answer the question: 'in the absence of educational homogamy, who would marry whom?' 'How difficult would it be for pairings to occur across educational groups?' Or, what would be the same, 'How easily do people marry across educational levels?' The answers to these questions are presented in figure 3 through a set of parameters that can be read as the odds of crossing the barriers to marriage between men and women from different educational groups. For illustrative purposes, only the crossing parameters corresponding to adjacent groups have been displayed in figure 3. For those marriages that take place between husbands and wives in non-adjacent educational groups, these crossing parameters must be added depending on the levels to be crossed.

These results suggest that association between educational attainment of the spouses has strengthened across cohorts for the two higher groups of the educational hierarchy and weakened for the two lower groups, although neither the trends nor the starting levels are the same for all educational barriers. The most remarkable trends are those observed among the higher educated. The odds of marriages in which one partner has tertiary education and the other higher secondary have decreased across cohorts and the same has happened for those marriages in which one partner has higher secondary and the other lower secondary. Thus tertiary education and higher secondary education have become less permeable barriers, decreasing the odds of intermarriage for these educational groups. At the lower end of the educational hierarchy, marriages in which one partner has at least lower secondary education and the other primary and marriages in which one partner has primary education and the other has not completed primary have slightly increased across cohorts, although the trend is slightly reversed for the last cohort. The lower barriers have become more permeable across cohorts, but the difficulty of crossing the lowest barrier (Primary not completed - Primary) has always remained the highest for all cohorts. An explanation, borrowed from Mare (1991), for this increase in permeability can be found in the fact that the proportion of these educational categories has fallen dramatically over time, and the average level of education within each group has increased. For instance, the internal composition of the 
'Primary not completed' group has changed over time. The proportion of men and women born between 1920 and 1929 who never went to school was close to $20 \%$, while for the younger cohorts this proportion was almost zero (Pérez 2001).

As a result of educational expansion, all in all, the most elevated barriers arise at the higher end of the educational distribution, progressively blurring the distinctions between those educational categories below higher secondary. The increasing permeability of the lower end barriers is consistent with the decreasing homogamy observed in Figure 3 for the three lower educational categories, while the decreasing permeability of the higher barriers is consistent with the increase in homogamy of the two highest educational categories. Finally, it is worth mentioning that although the top and the bottom of the educational distribution do follow opposite trends, we observe, at both ends of the educational distribution, that there are higher homogamy parameters and lower crossing parameters compared to the intermediate educational groups, which is a clear sign of polarization.

Figure 3: $\quad$ Crossing Parameters of Educational Assortative Mating by female birth cohort (log odds of Model 6)

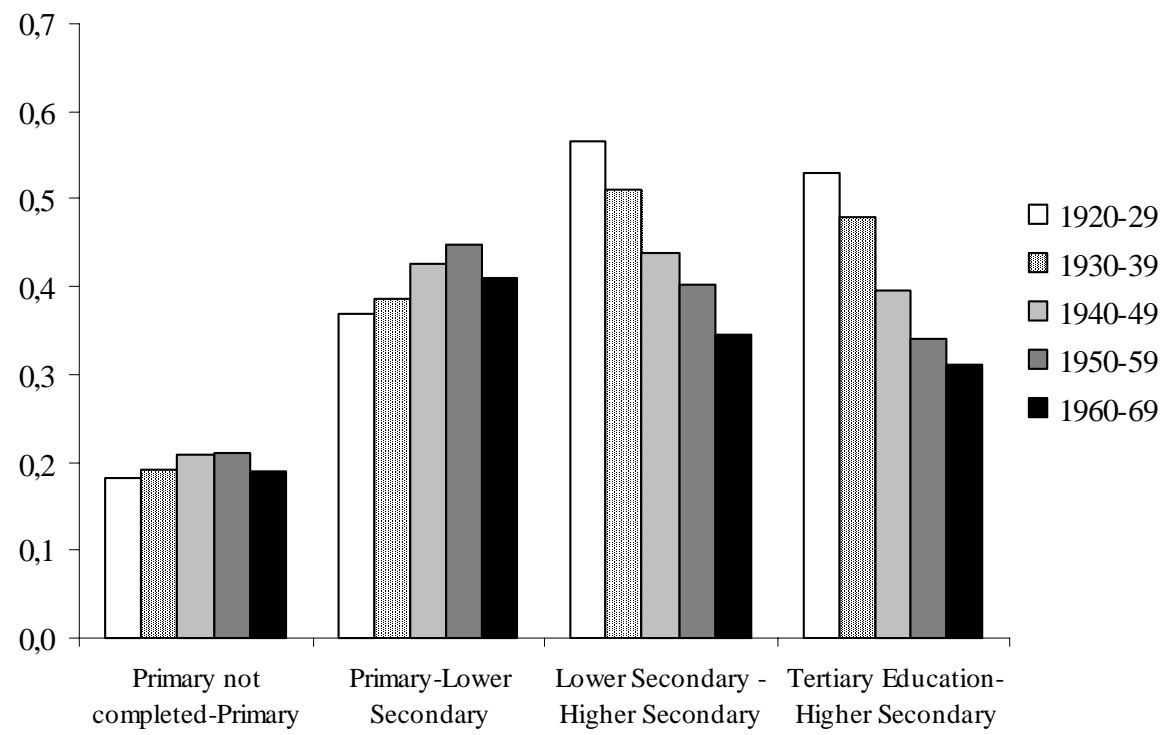




\subsection{Disappearance of the traditional hypergamic female marriage pattern}

We will now analyze unions formed by partners of different levels of educational attainment. We are mostly interested in knowing whether heterogamic patterns are similar between men and women. During the first half of the XXth century, women tended to marry up (that is with more educated husbands), in contrast to men (see Table 1). The proportion of hypergamic unions for women is higher than for men. We can now ask whether this pattern is the product of the unequal distribution of male and female schooling or rather the result of marked social patterns. Models 7 to 10 in Table 2 explore whether assortative mating patterns are symmetric net of the changes imposed by transformation in male and female educational attainment.

Model 7 assumes that interaction patterns between partners are symmetric, which means the odds of a marriage between two individuals of unequal schooling are unaltered by whether the husband or the wife has higher schooling. Model 8 adds an asymmetry parameter. This parameter allows for a uniform tendency for women to marry up or down (hypergamy and hipogamy, respectively) across combinations of different schoolings of partners (Mare, 1991, p.22). But model 7 and 8 constrain this symmetry to being constant across cohorts, which means they fail in terms of fitting the data.

Model 9 also keeps symmetry constant across cohorts but allows for specific cohort asymmetry parameters. The BIC criterion is highly sensitive to this change. Losing only 4 degrees of freedom, the BIC passes from 174 in model 8 to -183 in model 9, showing that the parameters produced capture major cohort transformations. Finally, model 10 also estimates cohort specific parameters. This change has positive effects on the BIC criterion but not as important as the ones observed in model 9 with respect to model 8 . Therefore, it is totally appropriate to conclude that younger cohorts have changed the traditional pattern of heterogamy.

The asymmetry parameters obtained by model 10 offer a synthetic but illustrative measure of the significance of this transformation by cohorts: the remarkable differences between the odds of men and women pairing with someone with more or less schooling shrink to the point of disappearing. The parameter (see figure 4) is net of the marginal distributions of the table and expresses that the odds of marrying up were higher for women than for men for all cohorts except for the youngest one. This process of constant and solid reduction allows us to reject the traditional female hypergamic pattern for the youngest cohort and accept our initial hypothesis of gender symmetry. 
Figure 4: $\quad$ Female Hypergamy Parameter by female birth cohort (log odds of Model 10)

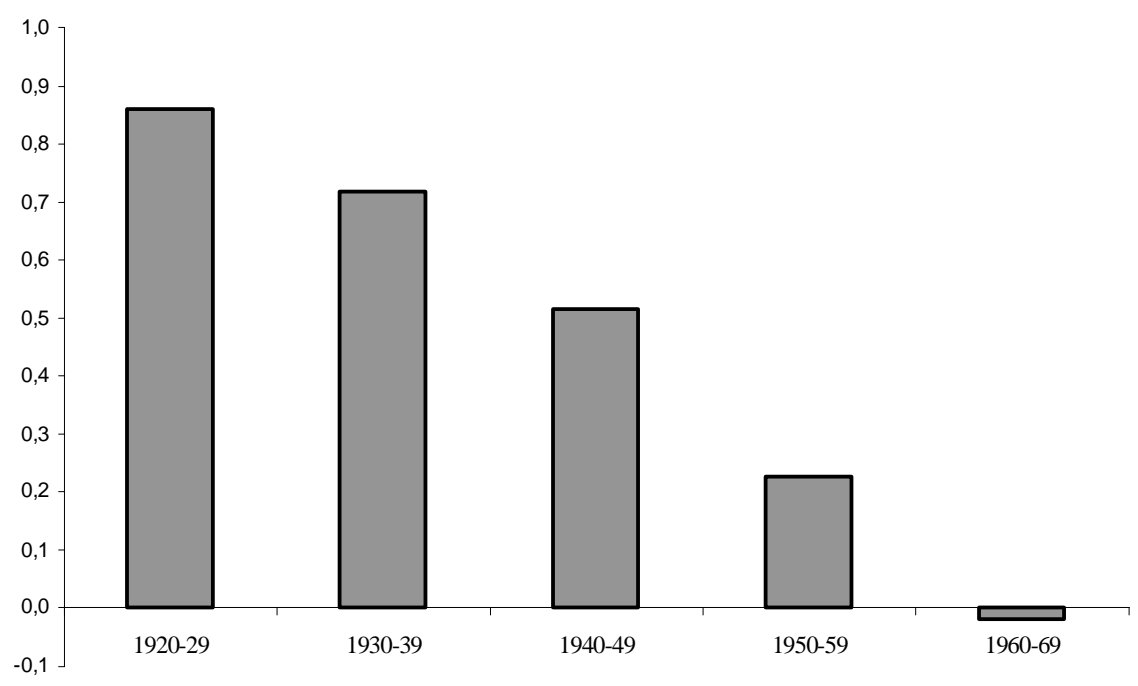

\section{Summary and discussion}

In this paper we have studied the patterns and trends of educational assortative mating in contemporary Spain with the main purpose of demonstrating that people do not mate at random but instead do so assortatively. Nevertheless, the idea of random mating has been helpful for analytical purposes because it has provided a contrast between independence and observed pairings. By this means, we have shown that the level of educational attainment influences mating options: net of the effect of changes in the educational attainment of partners, a clear propensity to enter homogamous unions is present in all cohorts. This propensity, however, differs across cohorts and between educational groups. For instance, in the context of globally decreasing homogamy, the increase in homogamy levels among higher educated men and women must be noted. Changes in heterogamic unions are also significant because we have shown that the traditional pattern of female hypergamy no longer prevails.

Future research should include other variables, which will improve our analysis. Variables such as the timing of marriage would add more insight to our results and help us answer questions about the role of delaying the age of marriage in explaining the 
increase in educational homogamy among the higher educated, but this information is not yet available. Besides, our analysis has dealt with all unions together. Even if there were still relatively few consensual unions in the cohorts analyzed meaning that their particularities could not affect the global patterns, there is no doubt that their prevalence will tend to increase in the immediate future and that would require new analyses dealing with unions separately by type.

Patterns and trends of educational homogamy in Spain are consistent with those found in the literature and with our initial research expectations. As in those societies where the educational structure has expanded, in Spain we observe that a) educational diversification has led to a reduction of global homogamy levels, b) an increase of the number of highly educated people increases the propensity for them to marry homogamously with each other and c) the reduction in differences between the educational distribution of men and women has reduced the pattern of female hypergamy. Somehow, although the loglinear model control for changes in educational distribution, the causes that will later drive the educational mating process are already embedded in the process of educational expansion, especially in those societies, like Spain, that are ethnically and religiously homogenous. We could even dare to say that all those changes were in fact implied in the same process of educational expansion, and that therefore, the evolution of educational homogamy patterns in Spain during the $\mathrm{XXth}$ century has been a chronicle of a transformation foretold.

So, in the future, considering the current trends and prospects of educational attainment among young cohorts, we expect global homogamy and specific homogamy for the higher educated to intensify because of the increasing number of university graduates. This will lead towards a polarization of the marriage market. However, Spanish society is becoming more ethnically and religiously heterogeneous and therefore, education may play a different role in shaping the mating process as observed in other societies, especially in the US. As data becomes available, it will be worth exploring how social exchange theories between immigrant and non immigrant population fits in the Spanish case and how education interplays with other variables, such as place of birth, religion, ethnicity, citizenship, which until now were not relevant for understanding assortative mating in Spain.

\section{Acknowledgments}

The authors are grateful to Prof. Robert McCaa and to the reviewers for their highly useful comments on this article. This article was partly funded by the "Migraciones internas, constitución familiar y empleo: dinámicas temporales y territoriales" project (SEJ2004-01534) of the Spanish Ministry of Science and Education. 


\section{References}

Becker, G. (1981). A Treatise on the family. Cambridge: Harvard University Press.

Birkelund, G. E., Heldald, J. (2003). "Who Marries whom? Educational Homogamy in Norway". Demographic Research (Max Planck Institute), 8,1.

Blackwell, D.L. (1998). "Marital homogamy in the United States: The influence of individual and parental education", Social Science Research, 27:159-188.

Blossfeld, H.-P.; Timm, A. (eds.). (2003). Who marries whom? Educational Systems as Marriage Markets in Modern Societies. Vol. 12, Netherlands: Kluwer Academic Publishers.

Cabré, A. (1993). "Volverán tórtolos y cigüeñas". in Garrido, L., Gil Calvo, E. (eds.), Estrategias familiares. Madrid: Alianza Editorial: 113-131.

Carabaña, J. (1994). "La constante homogamia educativa". Economia y Sociedad, 11: 43-66.

Cortina, C. (2004). Nivell educatiu, origen geogràfic i nacionalitat en la composició de la les parelles a Espanya. Una aproximació a l'estudi de l'homogàmia i l'endogàmia. Universitat Autònoma de Barcelona, Departament de Geografia. Mimeo.

Esteve, A.; McCaa, R. (2005). "Homogamia Educacional en México y Brasil, 19702000: Pautas y Tendencias". XXV International Population Conference. IUSSP. Tours.

Esteve, A. (2005). "Tendencias en homogamia educacional en México: 1970-2000". Estudios Demográficos y Urbanos, 59/20(2).

Forsé, M., Chauvel, L. (1995). "L'évolution de l'homogamie en France". Revue française de sociologie, XXXVI: 123-142.

González, M.J. (2001). The Interplay between Ocupational Career and Family Formation in Spain. PhD Dissertation at the Social and Political Sciences Department of the European University Institute. (mimeo)

González, M. J. (2003). "Who Marries Whom in Spain?". in H.-P. Blossfeld; A. Timm (eds.), Who Marries Whom? Educational Systems as Marriage Markets in Modern Societies. Vol. 12 Holland: Kluwer Academic Publishers, pp.57-78.

Halpin, B.; Chan, T. W. (2003). "Educational homogamy in Ireland and Britain: trends and patterns". British Journal of Sociology. 54(4): pp. 473-495. 
Kalmijn, M. (1991). "Status Homogamy in the United States". American Journal of Sociology, 97: 496-523.

Kalmijn, M. (1998). "Intermarriage and Homogamy: Causes, Patterns, Trends". Annual Review of Sociology, 24: 395-421.

Katrnák, T. (2005). "Educational Assortative Mating in the Czech Republic, Slovakia and Hungary between 1976 and 2003". Mimeo.

Knoke, D., Burke, P. (1980). Log Linear Models, Beverly Hills, Sage Publications.

Mare, R. D. (1991). "Five decades of assortative mating". American Sociological Review, 56,1: 15-32.

McCaa, R. (1993). "Ethnic intermarriage and gender in New York City". Journal of Interdisciplinary History, 24,2: 207-231.

Oppenheimer, V.K. (1988). "A Theory of Marriage Timing". American Journal of Sociology, 94, 3: 563-591.

Oppenheimer, V.K. (1994). "Women's Rising Employment and the Future of the Family in Industrial Societies". Population and Development Review, 20,2: 293342.

Pagnini, D.L., Morgan, S.P. (1990). "Intermarriage and social distance among U.S. immigrants at the turn of the century". American Sociological Review, 96: 405432.

Park, H. (2001). "Educational Homogamy in East Asian Countries: Patterns and Trends". International Sociological Association Meeting. Berkeley. Mimeo.

Pérez, J. (2001) Transformaciones demográficas en los recorridos hacia la madurez. $\mathrm{PhD}$ Dissertion at the Universidad Nacional a Distancia (UNED), Departamento de Sociología II. Mimeo.

Qian, Z. (1998). "Changes in Assortative Mating. The Impact of Age and Education, 1970, 1990". Demography, 35, 3: 279-292.

Schwartz, C.; Mare, R. D. (2004). "How do Marriage, Divorce, and Educational Upgrading Affect Trends in Educational Assortative Mating?". Population Association of America Conference. Boston.

Schwartz, C.; Mare, R. D. (2005). "Trends in Educational Assortative Marriage from 1940 to 2003". Demography. 42(4): pp. 621-646. 
Esteve \& Cortina: Changes in educational assortative mating in contemporary Spain

Smits, J., Ultee, W., Lammers, J. (1998). "Educational homogamy in 65 countries: an explanation of differences in openness using country-level explanatory variables". American Sociological Review, 63: 264-285. 